\title{
ALGUNAS REFLEXIONES EN TORNO A LOS BIENES COMUNALES
}

\author{
POR \\ Eloy Colom Piazuelo \\ Seminario de Derecho Administrativo \\ Facultad de Derecho de Zaragoza
}

\begin{abstract}
SUMARIO: I. Gratuidad de los bienes comunales.-II. Ambito espacial de los bienes comunales.
\end{abstract}

La nueva legislación sobre régimen local no ha variado sustancialmente la configuración de los bienes municipales (1). Así, si comparamos las definiciones de bienes propios y bienes comunales en la Ley de Régimen Local de 3 de diciembre de 1955 y en la Ley Reguladora de las Bases de Régimen Local, de 23 de abril de 1985, que deroga la anterior, comprobamos que son prácticamente iguales. Ello puede ser consecuencia del acierto de nuestros legisladores, que hace innecesario todo cambio, al lograr expresar juridicamente las caracteristicas especiales de un tipo de bienes, pero también puede deberse a otros motivos no tan loables ni ser adecuada en la actualidad su mantenimiento, al menos en los mismos términos.

Esta posibilidad de poner en duda los límites legales de las distintas clases de bienes municipales no es fácil que se nos plantee, puesto que la existencia exclusivamente de estudios jurídicos sectoriales de los bienes municipales desvía nuestro interés a la resolución de otros problemas distintos. Por ello, la lectura de un reciente libro (2), primero que aborda en su conjunto todos los bienes de las Entidades locales, me ha sugerido una serie de preguntas sobre el sentido de la actual clasificación legal. Preguntas cuya contestación sólo es posible aventurar, dado que requeriría un análisis más profundo y pausado que el resultante de las reflexiones surgidas de la lectura del citado libro.

Para una mejor comprensión de la razón que justifica estas consideraciones, comparemos las definiciones de los bienes comunales y bienes de propios, teniendo en cuenta la interpretación jurisprudencial de las mismas: son bienes comunales aquellos cuyo aprovechamiento gratuito pertenece a los vecinos y la titularidad al

(1) La legislación de régimen local califica los bienes comunales como bienes demaniales, sin embargo no modifica la definición de estos bienes.

(2) Chacón ORTEGA, L.: Bienes, derechos y acciones de las Entidades locales. Editorial Bayer Hermanos, S. A., Barcelona, 1987, 830 pp. 
Municipio, y bienes de propios aquéllos que pueden constituir fuente de ingresos o renta que no sean de dominio público.

Ambas nociones, en una primera lectura, pueden parecernos bastante claras, sin embargo, no es así, puesto que la jurisprudencia realiza diferentes interpretaciones. Así la Sentencia de 31 de diciembre de 1966 de la Sala Tercera del Tribunal Supremo decide sobre un caso curioso, descrito en parte en uno de sus considerandos: «que la finca aparece inscrita en el Registro de la Propiedad a nombre del Ayuntamiento (...), que las masas de pinos talables que constituyen su riqueza arbórea explotable son sacados periódicamente a subasta por el Ayuntamiento, sin que, por lo demás, quede habiendo nunca rematantes en ellas; que, por lo mismo, es el Ayuntamiento el que procede al destino de tal producto del monte; y que éste se hace distribuyéndolo (...) entre la caja municipal y los patrimonios particulares de los vecinos». A continuación la Sentencia define los bienes de propios y comunales de forma similar a las nociones anteriores, advirtiendo que estos últimos bienes pueden adjudicarse por subasta o pueden establecerse unos cánones o cuotas vecinales para compensar los gastos de conservación, custodia y administración de estos bienes, pero no cantidades superiores. Como existe' este límite máximo de las cantidades que el Ayuntamiento puede percibir el Tribunal no puede decir que toda la finca es un bien comunal: «conjugando uno y otros preceptos de las Leyes de Régimen Local y de la Contribución estatal con el modo de ser y de explotarse tal finca y sus rendimientos (...), se llega a la conclusión de que estamos ante una finca, unitaria sí, pero de aprovechamiento fraccionado en dos partes: una, en provecho de las arcas municipales, que lleva implícita la calificación de un destino de productos que responde 0 a un concepto de "bienes de propios" o a uno de los bienes comunales "productores de renta" (...), y de otra, en provecho personal e individualizado de todos y cada uno de los vecinos del Municipio, conceptuación peculiar de los "bienes comunales" (no productores de renta)». Es curiosa la distinción dentro de los bienes comunales entre aquellos productores de renta y aquellos totalmente gratuitos; máxime se se definen como aquellos cuyo aprovechamiento es de los vecinos independientemente de las cantidades percibidas por el Ayuntamiento. Aplicando el criterio contenido en esta Sentencia, si el canon supera ese tope en una cantidad insignificante, cambiará de naturaleza ese año, pero si al año siguiente no lo supera, volverá a constituir un bien comunal. Sin embargo existen otras sentencias que exigen la total gratuidad de los bienes rígidamente, calificando como bien de propios si se arbitra dicho bien, como la Sentencia de la Sala de la Contencioso de 13 de mayo de 1947, que posteriormente se comentará. Esta imprecisión hace necesario saber qué alcance tiene la exigencia de la 
gratuidad de los aprovechamientos comunales y su posible compatibilidad con los cánones o cuotas $\mathrm{y}$, además, el significado de la palabra «renta» o «ingreso», esencial para entender los bienes de propios. Pero no sólo sorprende este punto concreto en la Sentencia citada, sino la afirmación de que el aprovechamiento de los bienes comunales debe realizarse por todos y cada uno de los vecinos; ello impediria considerar como bien comunal aquel cuyo aprovechamiento fuese realizado por un núcleo de población dentro del Municipio sin constituir una Entidad local menor. Por tanto, la distinción entre bien comunal y bien de propios no está tan clara como en un principio se esperaba. Sobre ambos puntos expondré a continuación una serie de reflexiones.

Este no es el único problema, puesto que la definición actual de tales bienes incide principalmente en que el aprovechamiento de estos bienes sea de los vecinos, pero surge la pregunta de la razón jurídica de esta definición tan concreta; ello, además, sin olvidar que los bienes comunales en la nueva legislación local son bienes de dominio público. Este tema volveré a considerarlo más adelante, pero antes precisemos los conceptos de bien comunal y bien de propios. Debe advertirse antes de iniciar la exposición que las afirmaciones que realizo a continuación son sólo meras reflexiones y que, por tanto, no deben considerarse como teorías totalmente elaboradas.

\section{GRATUIDAD DE LOS BIENES COMUNALES}

Los bienes de propios se han definido tradicionalmente como aquellos que pueden constituir renta para el Municipio (3), y los bienes comunales, como aquellos bienes cuyo aprovechamiento gratuito corresponde a los vecinos. De esta forma, históricamente siempre se ha dudado si los aprovechamientos comunales arbitrados son bienes comunales o bienes de propios.

En el fondo, el problema reside en lo que se entiende por renta en favor del Municipio, es decir, renta como cualquier ingreso independientemente de la naturaleza que tenga y del origen, siempre que recaiga sobre determinados bienes, o renta como utilidad o beneficio que rinde anualmente una cosa o de lo que de ella se cobra. Estos dos significados de renta trastocaron en el siglo xIX las definiciones de bienes comunales y de propios, y esta confusión perdura en nuestro siglo. Pero se comprenderá mejor esta afirmación con la lectura de las dos Reales Ordenes que se transcriben a continuación:

(3) La Ley 10, titulo 28, partida 3, se refería a los bienes de propios de la siguiente forma: "Campos, e viñas, e huertas, e oliuares, e otras heredades, e ganados, e siervos, e otras cosas semejantes que dan fruto de si, o renta, pueden auer las cibdades.» 
Real Orden de 16 de noviembre de 1854 (GOB):

«Vista la consulta que V. S. elevó a este Ministerio en 7 de septiembre del año pasado 1853, sobre si debían entenderse bienes de propios para el pago del 20 por 100 de sus productos, además de los reconocidos por tales en los reglamentos del ramo, los de aprovechamiento común que se encuentren o hayan sido arbitrados. Y considerando que éstos no han tenido ni pueden tener el carácter de bienes de propios para el efecto de contribuir al Estado con cantidad alguna, porque su aprovechamiento es gratuito y cuando los Ayuntamientos han conseguido autorización para imponerles algún gravamen, ha sido por vía de arbitrio para cubrir el presupuesto municipal, S. M. la Reina se ha servido resolver que sólo se exija el 20 por 100 de los productos a los bienes de propios reconocidos tales por los reglamentos del ramo, y de que los comunes de los pueblos cuando sean arbitrados se exija solamente el 5 por 100 , como se exige de los arbitrios en general.»

En cambio la Real Orden de 23 de abril de 1858 (GOB) contradice la anterior:

«Las secciones de Gobernación y Fomento y de la Hacienda del Consejo Real, a las que tuvo por conveniente oír S. M. en el expediente instruido en este Ministerio, con motivo de diferentes consultas y dudas ocurridas sobre si las fincas de común aprovechamiento de los pueblos, cuando son arbitradas por los Ayuntamientos para atender a los gastos municipales, deben pagar el 5 o el 20 por 100 de sus productos, han dado su dictamen en los términos siguientes:

Considerando que, según nuestras leyes, nunca debieron ni pudieron reputarse como bienes de propios sino aquellos que, perteneciendo al común de la ciudad o pueblo, daban de sí algún fruto o renta en beneficio del procomunal del mismo, y de los cuales nadie en particular puede usar;

Considerando que bajo este concepto es inadmisible la doctrina o fundamento de las Reales Ordenes de 17 de enero de 1849 y 16 de noviembre de 1854 , ya porque en los reglamentos formados a los pueblos en 1763 por el Consejo de Castilla, no solamente se comprendieron las fincas de propios, sino las del común que a la sazón estaban arbitradas; ya porque como bienes comunes sólo se entendían y han debido entenderse siempre, según las indicadas leyes, aquellos de que cada vecino de por sí pueden usar gratuita y libremente, que 
no se han arrendado ni arriendan, y cuyo disfrute o aprovechamiento, además de ser común a todos los vecinos era gratuito, como se dice en la citada resolución de 6 de noviembre de 1854 ;

Considerando que los pueblos arbitraban y han arbitrado en todos tiempos, con la competente autorización, para cubrir el déficit de su presupuesto, tierras o pastos comunes o de aprovechamiento común, que es lo mismo, unas veces arrendando el sobrante de dichos pastos, otras permitiendo el rompimiento de tierras para repartirlas en suertes, entre los vecinos, o rematarlas en el mejor postor; ya, en fin, dando facultad para la corta o entresaca de árboles, rozas y descuajos, con cuyos arbitrios obtenían una renta en favor de la comunidad del pueblo;

Considerando que cualquiera que sea o haya sido el título de adquisición de tales bienes, en el hecho de arbitrarse o de haber sido arbitradas, privándose los vecinos del uso o común disfrute de sus aprovechamientos dejan de ser bienes comunes, y adquieren aunque sea temporalmente el carácter y naturaleza de los de propios, porque vienen como éstos a constituir una renta en beneficio del procomunal.»

Decidiendo finalmente que se hallan sujetos al pago del 20 por 100 de propios:

«No solamente aquellas fincas rústicas de propiedades de los pueblos que, no estando destinadas al aprovechamiento común y gratuito de los vecinos, producen o pueden producir una renta en favor de la comunidad del pueblo, cualquiera que sea o haya sido su origen y denominación, sino los que, aun siendo de común aprovechamiento, se hallen arbitradas o lo sean por los Ayuntamientos, con la correspondiente autorización para obtener por este modo alguna utilidad o recurso aplicable a los gastos municipales.»

Si se lleva al extremo esta interpretación las cantidades percibidas por el uso privativo del dominio público constituirían renta, y ello supondría un cambio en la naturaleza de estos bienes.

Esta última interpretación del concepto de renta todavía se mantiene en la Sentencia de la Sala de lo Contencioso de 13 de mayo de 1947 al discutirse el concepto de bien comunal a efectos de respetar la exención del impuesto del 20 por 100 . En ella se afirma: «que a pesar de discutirse la inexistencia de una perfecta clasificación en razón a su fin, de bienes municipales que forman su hacienda, es lo cierto que por distintas resoluciones administrativas y judiciales se ha 
llegado a determinar qué bienes comunales son aquellos que cada vecino puede usar gratuitamente, siendo bienes de propios los que rinden utilidad y no pueden los veninos usar de ellos más que conforme a los convenios establecidos»; pero después de realizar esta clasificación la Sentencia afirma, refiriéndose a unos bienes concretos y a la posibilidad de que se exijan derechos o arbitrios a todos los beneficiados por esos aprovechamientos, que al percibir rentas el Ayuntamiento por alguno de estos conceptos resulta «en este caso de perfecta aplicación o dispuesto en la Real Orden de 23 de abril de 1858 , sujetando al 20 por 100 de propios aquellas propiedades de los pueblos que produzcan una renta cualquiera que sea su origen».

La influencia de esta definición perduró durante todo el siglo XIX, extendiéndose a otros ámbitos, como la legislación desamortizadora. A pesar de que dichas normas declaraban en estado de venta todos los bienes municipales y exceptuaban de la misma los bienes comunales, no contenian una definición de tales bienes o los requisitos que debían reunir, al menos durante los diez primeros años de vigencia de dicha normativa (4). En este sentido, es curiosa la argumentación utilizada por la Sentencia de 6 de febrero de 1866 para considerar como bien comunal una finca:

«Considerando sobre este punto (la excepción de la venta por este concepto), que dicha ley no exceptúa de la venta de los bienes de aprovechamiento común, atendido su origen, sino aquéllos que se aprovechasen en común al tiempo de su promulgación;

Considerando que la Real Orden de 23 de abril de 1958 declaró que sólo los bienes cuyo disfrute fuese común y enteramente gratuito estaban exceptuados del pago del 20 por 100 de propios, quedando sujetos a él los que, siendo de aprovechamiento común, se hallaban arbitrados para obtener alguna utilidad o recurso aplicable a los gastos municipales;

Considerando que en virtud de dicha declaración vino a quedar consignado, en conformidad al principio establecido en la Ley de Partida, que los bienes arbitrados o que daban renta, que debia ser «metida en el procomunal» quedaban sujetos a la condición de los bienes de propios, aunque en su origen, o por los títulos de su adquisición, hubiesen sido de común aprovechamiento,

$Y$ considerando que según los datos reunidos en el expediente, y aun los aducidos por los demandantes en la vía

(4) La Ley de 1 de mayo de 1855, en el artículo 1, declaraba en estado de venta los propios y comunes de los pueblos, exceptuando en el artículo 2.9, «los terrenos que son hoy de aprovechamiento común, previa declaración de serlo». 
contenciosa, las dehesas (...), a la fecha de la Ley de 1 de mayo de 1855 , y mucho tiempo antes, no se disfrutaban en sus aprovechamientos en común y gratuitamente, sino mediante una renta, mayor o menor, aplicada a cubrir las necesidades de los Municipios, y que por lo mismo no están comprendidos en la excepción del número $9 .^{\circ}$ del artículo 2.9$)$

Utilizar y aplicar una interpretación de bien comunal realizada a efectos fiscales no es correcto, puesto que ambos conceptos de bien comunal pueden no coincidir y los tribunales entender que no es aplicable. Por ello el artículo 4 del Real Decreto de 10 de julio de 1865 sustituye la definición de aprovechamiento comunal citada por la necesidad de aportar una serie de datos para que el Gobierno excluya esa finca de la desamortización. Estos requisitos consisten en la prueba de la propiedad por parte de los Municipios y la acreditación del ejercicio libre y gratuito por parte de todos los vecinos en los veinte años anteriores a la Ley de 1 de mayo de 1855. Ambos requisitos permiten una aplicación del principio de gratuidad menos rigurosa que la contemplada en la Real Orden de 23 de abril de 1858 citada.

Ello originó una jurisprudencia contencioso-administrativa más favorable; así, la Sentencia de 22 de febrero de 1907 afirmaba que para que los bienes de los pueblos no sean tenidos como de propios es indispensable, según los artículos 1 de la Ley de 1855, 4 del Real Decreto de 10 de julio de 1865 , etc., que el aprovechamiento haya sido libre y gratuito, sin interrupción alguna, y, según la jurisprudencia más benévola, que si alguna vez se han arbitrado, lo hayan sido por circunstancias marcadamente extraordinarias, nunca con carácter constante e inmemorial para cubrir las atenciones corrientes del Municipio. Esta interpretación beneficiosa para los Municipios no siempre se respetó, puesto que en Sentencias como la de 11 de enero de 1867 se exigen no sólo los requisitos del artículo $4 .^{\circ}$ del Real Decreto de 1865 , sino también no haber satisfecho el impuesto del 20 por 100.

Tanto la legislación fiscal como en la legislación desamortizadora el problema reside en lo que se entienda por renta porque de ello depende que se califique como bien de propios o comunal; problema que no sólo se plantea en esos dos sectores, sino también en otros como en la interpretación de las exclusiones del pago de la contribución territorial.

Es curioso, e incluso sorprendente, que las normas citadas no tuvieran en cuenta las previsiones recogidas en la legislación de régimen local. Si analizamos, aunque sólo sea someramente, las 
distintas leyes municipales desde finales del siglo pasado, comprobamos cómo se exige que el aprovechamiento sea gratuito y se permite el establecimiento de unos cánones o cuotas, sin que ello suponga una alteración de su naturaleza o del principio de gratuidad:

- La Ley Municipal del 20 de agosto de 1870 prevé en el artículo 70.4 dichos cánones sobre bienes comunales: «En casos extraordinarios, y cuando las atenciones del pueblo asi lo exijan, puede el Ayuntamiento acordar la subasta entre vecinos de los aprovechamientos comunales propiamente dichos o fijar el precio que cada uno ha de satisfacer por el lote que haya sido adjudicado.»

- La misma previsión está contenida en la Ley Municipal de 2 de octubre de 1877, en su artículo 75; el Estatuto Municipal de 8 de marzo de 1924, en su artículo 159, y el artículo 155 de la Ley Municipal de 31 de octubre de 1935.

- La Ley de Bases, de 17 de julio de 1945, en su base 19, introduce un cambio fundamental al limitar ese canon: «Los Ayuntamientos podrán señalar a los vecinos el pago de la cuota anual por el aprovechamiento de bienes comunales para compensar estrictamente los gastos que se originen de su custodia, conservación y administración.» En desarrollo de esta ley, el Texto Articulado de la Ley de Régimen Local, de 16 de diciembre de 1950, en su artículo 193, reproduce la base 19 , pero además introduce el carácter de excepcional y la necesidad de una mayoría de $2 / 3$ para su adopción. El contenido de este artículo se reproduce en el artículo 77 del Texto refundido de las disposiciones legales vigentes en materia de régimen local de 18 de abril de 1986.

Por tanto, tenemos conceptos distintos de bien comunal, dependiendo del sector material afectado; diferencias que residen exclusivamente en la interpretación de la palabra «renta» o «ingreso» como comprensivas solamente de las utilidades producidas o lo que se cobra o también aquellas cantidades que recaen sobre ese objeto, pero que tienen una naturaleza y justificación diferente (5).

(5) Este arbitrio tiene una justificación diferente, puesto que obedece a necesidades de cubrir déficit municipal, evitando los repartos vecinales y atribuyéndolos de forma proporcional a los beneficios recibidos; en este caso es temporal. Sin embargo, tambièn puede obedecer a que su aprovechamiento sólo beneficie a una parte del vecindario, debido a que no ejercen esa profesión; entonces, para que no se produza un beneficio superior al percibido por otros vecinos se podria permitir establecer estos cánones. Esta posibilidad, sin embargo, no debe aprovecharse para elevar tanto la cuantía de los cánones, de forma que se convierten en verdaderos arrendamientos porque ello va en contra de la propia naturaleza de los bienes comunales. Por ello la ley navarra de bienes comunales no tiene mucho sentido al exigir el 90 por 100 de los precios habituales de arrendamiento en la zona. 


\section{AMBITO ESPACIAL DE LOS BIENES COMUNALES}

1. Los bienes comunales son aquellos bienes propiedad del Municipio cuyo aprovechamiento pertenece a los vecinos. No obstante, es posible preguntarnos si son todos los vecinos o puede restringirse a los vecinos de determinado núcleo de población de un término municipal. La legislación de régimen local no se pronuncia expresamente, aunque sí implícitamente, porque el artículo 79 de la Ley Reguladora de las Bases de Régimen Local, de 2 de abril de 1985, en relación con el artículo 18.1 c) de la misma ley, determina que el aprovechamiento corresponde a todos los vecinos; únicamente el Texto Refundido de 18 de abril de 1986 incluye una excepción para un supuesto concreto, como más adelante se indicará. Estas mismas previsiones se establecen para las Entidades locales menores.

La no admisión de la restricción geográfica es lógica si se piensa que estos núcleos beneficiados por los aprovechamientos pueden constituirse en una Entidad local menor; pero esta posición puede ser demasiado simplista, como nos recuerda el profesor AlEJANDRo NiETo en su libro titulado Bienes comunales (6) al intentar explicar un supuesto fáctico: «sucede con mucha frecuencia que núcleos sociales sin carácter jurídico de Municipio ni de Entidad local menor siguen administrando de hecho por sí mismos sus bienes comunales, por no haberse traspasado las competencias de las antiguas juntas administrativas a los órganos municipales o, más sencillamente, ni siquiera existiesen en un tiempo tales juntas administrativas y los bienes comunales se regulan por órganos -más o menos formalmente constituidos-, pero, en todo caso, al margen de la ley, al parecen».

Esta imposibilidad de comprender estos supuestos en el concepto de bien comunal no estaba prevista en la legislación de régimen local de fines del siglo XIX, puesto que tiene su origen en el presente siglo. Así, examinando la Ley Municipal de 20 de agosto de 1870, comprobamos que prevé varias posibilidades en los artículos 25,70 y 85 . En concreto, el artículo 25 dice al especificar los derechos de los vecinos: «Todos los vecinos tienen participaciones en los aprovechamientos comunales y en los derechos y beneficios concedidos al pueblo, así como están sujetos a las cargas de todo género que para los servicios municipales y provinciales se impongan, en la forma y proporción que esta ley determina.» Dice todos los vecinos y no solamente los de una zona concreta, al igual que en el articulo 70. En cambio, en el artículo 85 se establece que «los pueblos que, formando con otro término municipal, tengan territorio propio, aguas, pastos,

(6) Nieto, A.: Bienes comunales. Ed. Revista de Derecho Privado, 1964, pp. 771 y ss. 
montes o cualesquiera derechos que les sean peculiares, conservarán sobre ellos su administración particulan. Con lo cual existen aprovechamientos comunales de ámbito inferior al término municipal. Estas mismas previsiones se repiten en la Ley Municipal de 2 de octubre de 1877 en los artículos 26, 75, 90 y 96.

El Estatuto Municipal de 8 de marzo de 1924 introduce importantes modificaciones al regular las Entidades locales menores, responsables de los aprovechamientos comunales (arts. 4, 105 y ss., 190 y 191) (7), teniendo en cuenta, además, que la disposición transitoria 8. ${ }^{\mathrm{a}}$ establece que «los anejos que al publicarse esta ley existan y se rijan con arreglo al artículo 90 y siguientes de la de 2 de octubre de 1877 , tendrán, desde luego, carácter de Entidades locales menores». Por lo tanto, esta ley prevé la conversión en Entidades locales menores de todos aquellos supuestos en que existian estas peculiaridades territoriales, dejando de regular los bienes comunales cuyo aprovechamiento pertenezca a un núcleo de población de un Municipio y no se constituya en Entidad local menor. Esta regulación no varía en la Ley Municipal de 31 de octubre de 1935, en sus artículos 35 y 155 y 67 y siguientes, en la Ley de Régimen Local, de 3 de diciembre de 1955, en sus artículos 192 y 193 y el Texto refundido de las disposiciones vigentes en materia de Régimen Local de 18 de abril de 1986, en sus artículos 75 y 77 .

Este es el contenido de la regulación general, pero debe advertirse que el artículo 75.4 del Texto refundido de 18 de abril de 1986, correspondiente al artículo 192.4 de la Ley de Régimen Local, de 3 de diciembre de 1955 , incluye una previsión distinta para un caso especial de aprovechamiento comunal al posibilitar que se establezca como requisito previo unas especiales condiciones. La redacción de ambos artículos procede de la Ley de 23 de diciembre de 1948 y tiene como antecedente el Real Decreto de 8 de abril de 1930. Estas restricciones geográficas de los beneficiarios constituyen una excepción admitida por el legislador para evitar ciertas consecuencias no queridas, como expresamente indica la exposición de motivos de la citada Ley de 23 de diciembre de 1948:

«Algunos Municipios y Entidades locales menores, propietarios de montes que fueron adquiridos por el común de vecinos, vienen practicando tradicionalmente la costumbre de conceder a todos los que lo son en la actualidad el disfrute gratuito de los diversos aprovechamientos, siquiera limitando

(7) La Sentencia del Tribunal Supremo de la Sala Tercera de 1 de febrero de 1928 dice que las Juntas vecinales tienen facultades privativas para regular, con sujeción a los preceptos estatutarios correspondientes, el aprovechamiento de los bienes comunales de la exclusiva pertenencia del pueblo a que aquéllos representan. 
la concesión de cuotas periódicas de madera a los residentes que reúnan, además de la vecindad, otras condiciones de arraigo señaladas de antiguo.»

La incompatibilidad de esta costumbre con el párrafo primero del artículo 159 del Estatuto Municipal que otorgaba el derecho al disfrute de los bienes comunales a todos los vecinos, sin distingos ni restricciones, fue resuelta y obviada mediante el Real Decreto de 8 de abril de 1930, que modificaba la redacción del citado artículo en el sentido de dejar subsistente el sistema de aprovechamiento de los bienes comunales que dichos Ayuntamientos y Juntas vecinales venían poniendo en práctica, si bien con la obligación de regularlos estrictamente mediante Estatutos u Ordenanzas especiales que debían ser sometidos a la aprobación del Ministerio de la Gobernación, siempre que se opusieran a las normas establecidas en la Ley.

El preámbulo de esta disposición recogía los informes del Consejo Forestal, Dirección General de Administración Local y Consejo de Estado, todos ellos favorables a la adopción de tal medida que se estimaba indispensable no sólo para la conservación de los patrimonios de los Municipios o Entidades locales menores afectados, sino para la subsistencia de sus vecinos nativos carentes de otros medios de vida, ya que la aplicación rígida del artículo 159 del Estatuto Municipal daba lugar a que muchos forasteros, sin vínculo alguno con dichos Entes locales; viniesen a residir en su término para obtener la condición legal de vecinos, tras breve lapso de residencia, con la exclusiva finalidad de participar en los beneficios de las cortas periódicas de los montes comunales.

Posteriormente, la redacción del artículo 155 de la Ley Municipal de 31 de octubre de 1935, al no recoger el contenido de este Real Decreto, reducido a la categoria de precepto reglamentario válido mientras no se opusiera a una Ley votada en Cortes, vino a reproducir el problema, agravado actualmente por el incremento del valor de la madera, que hace prácticamente imposible el sistema tradicional de aprovechamiento de los montes interin su disfrute no regule por unas normas que tiendan a encauzarlo en el doble sentido de exigir determinados requisitos a los beneficiarios, aparte su inscripción en el padrón de vecinos, y cuidar de que tales bienes no sufran menoscabo y sus productos sean destinados preferentemente a mejoras colectivas que a todos alcancen.

Es singularmente propicia para ello la circunstancia -que marca un acertado criterio de vuelta a lo tradicional- de que 
la base 19 de la Ley de Régimen Local, de 17 de julio de 1945, pendiente aún de desarrollar en texto articulado, torna a dar primacía a las costumbres o reglamentaciones particulares de carácter local sobre las normas generales que regulan el aprovechamiento de los bienes comunales.»

Estas especiales condiciones de permanencia pueden interpretarse en el sentido de permanencia previstas por esta excepción temporal durante una serie de meses cada año en el Municipio o permanencia espacial en una zona concreta del término municipal. Esta última posibilidad es adoptada, por ejemplo, en la Sentencia de la Sala Cuarta del Tribunal Supremo de 12 de febrero de 1959 (8) al afirmar:

«Que el artículo 192, número $4 .^{\circ}$, de la Ley de Régimen Local, al transcribir el artículo único de la Ley de 23 de diciembre de 1948, inspirada a su vez en el presente Real Decreto-Ley de 8 de abril de 1930, se aparta del criterio rígidamente igualitario reflejado en los artículos 159 del Estatuto Municipal de 8 de marzo de 1924 y 155 de la Ley municipal de 31 de octubre de 1935, a fin de respetar los sistemas tradicionales de ordenación del disfrute y aprovechamientos de montes comunales; permitiendo así la pervivencia de normas consuetudinarias o reglamentaciones locales tradicionalmente observadas en la materia, aunque exigiesen determinadas condiciones de vinculación, arraigo, permanencia o edad, además de la vecindad en los beneficiarios; siempre que aquellas condiciones singulares y la cuantía máxima de las suertes o lotes se fijaran por los Ayuntamientos o Juntas vecinales en Ordenanzas de carácter especial a los que habria de prestar su aprobación el Ministerio de Gobernación, oído el Consejo.»

A continuación, al estudiar la posible incompatibilidad entre las Ordenanzas y la Ley de Régimen Local, añade:

«Que no se da en este caso el supuesto conflicto entre normas reglamentarias y legales que haya de resolver concediendo a las últimas la obligada preeminencia, pues los

(8) El supuesto de hecho se explica en la propia Sentencia al decir: «Siendo el único problema jurídico que el recurso plantea el de si los artículos 2 y 8 de meritada Ordenanza, al exigir como requisito esencial para que los vecinos puedan participar en el aprovechamiento el de su residencia en el casco urbano de la capitalidad del Municipio, y negar el derecho a los que hayan residido o residan en su término municipal, caserios, agregados o anejos». Para ello alegan la infracción de la Ley de Régimen Local por no respetar la definición del término municipal (art. 11), infracción de las normas que determinan las personas que son vecinos (art. 44) y no cumplir el requisito necesario de la costumbre (art. 192.4). 
artículos 11 y 4 de la Ley de Régimen Local, en razón a su generosidad, no cabe enfrentarla con los específicos que establecen las condiciones de participación vecinal con carácter restringido, apoyándose en el artículo 192 del propio ordenamiento legal que se estima vulnerado, cuando no se ha hecho otra cosa que aplicarlo correctamente, ya que entre las especiales condiciones de permanencia puede figurar la de que el beneficio alcance sólo a los vecinos residentes en determinado núcleo urbano, sin que ello implique, como se pretende, una inadmisibilidad y vejatoria discriminación topográfica respecto a los demás.»

Posteriormente analiza, como es una costumbre arraigada, cumpliéndose el requisito exigido por el artículo 192.4.

Esta misma previsión, como ya hemos dicho, está recogida en el artículo 75.4 del Texto refundido de la Ley de Régimen Local de 18 de abril de 1986; no obstante, al igual que ocurría con su antecedente, existe una limitación importante para su aplicación, puesto que las especiales características sólo se pueden exigir en los supuestos de cortas de madera. Por ello sorprende que algunas Sentencias afirmen que son bienes comunales los aprovechamientos vecinales restringidos geográficamente, independientemente del tipo de aprovechamiento. Como ejemplo baste citar la Sentencia de la Sala Cuarta de 27 de abril de 1963 sobre los aprovechamientos de pastos y leñas, no de cortas de madera, pertenecientes al pueblo de San Martín de Terroso, anexo comprendido dentro del Municipio de Terroso y no constituido en Entidad local menor. La Sentencia afirma sorprendentemente lo siguiente:

"Que tampoco se muestra ilegalidad alguna en la especificación del núcleo de población (San Martín de Terroso) a que corresponda el aprovechamiento, sobre todo cuando aquél no coincide exactamente con el conjunto de vecinos, ya que, por el contrario, los artículos 4 y 16 de la citada Ley de Montes, mandan se determine en el catálogo quiénes sean los beneficiarios ni con ello se invade la atribución municipal, pues el aprovechamiento y disfrute de bienes comunales en explotación colectiva o comunal que dispone el artículo 192 de la Ley de Régimen Local que se invoca, queda respetado, claro que entre los vecinos, dejando la distribución después a la competencia municipal.»

Curiosa forma de justificar el ámbito inferior, puesto que se acude a la Ley de Montes para reducir el ámbito y después aplicar los principios generales citados. 
La interpretación de esta Sentencia contrasta con la de la Sentencia de la Sala Cuarta de 18 de octubre de 1983, relativa a un aprovechamiento comunal de pastos:

«Que si ello es así no aparece diáfano el derecho exclusivo de los vecinos de una parroquia, pedania, etc., al pastoreo de su ganado vacuno y ni siquiera preferente a su ganado de uso propio en montes comunales; por el contrario, una interpretación razonable del artículo 243 del Reglamento de Montes y preceptos concordantes conduce a declarar que todos los vecinos del término municipal tienen derecho a todos los pastos con las limitaciones técnicas que imponga la Administración forestal, así como con las limitaciones que resulten de las que imponga el Ayuntamiento a través de sus Ordenanzas municipales, en las que ha de tenderse inexcusablemente a repartir con justicia e igualdad unas extensiones de terrenos o montes, naturalmente limitados.»

Por lo tanto, no pueden calificarse como bienes comunales en el sentido específico que realiza la Ley de Régimen Local. Entonces es posible preguntarnos qué calificación jurídica tendrá el aprovechamiento de pastos, por ejemplo, en un monte aragonés. En este caso el núcleo de población habrá prescrito a su favor el derecho real limitado, conforme a las normas de Derecho civil. Hecho que supondrá, a veces, que este bien no constituya fuente de ingresos para la entidad.

Esta obligatoriedad espacial sólo tiene sentido en caso de que el territorio y población municipal sea uniforme, pero si existe una pluralidad de núcleos independientes puede resultar que dicho planteamiento no sea conveniente; por ello sería necesario que la legislación previera la posibilidad, no reducida a un caso concreto, de comprender dentro del concepto de bien comunal todos los supuestos, evitando de esa forma interpretaciones jurisprudenciales forzadas. Por otra parte, si la exposición de motivos de la ley de 23 de diciembre de 1948 justificaba la reforma en la importancia económica de dichos. aprovechamientos madereros, piénsese que existen otros aprovechamientos, no muy importantes económicamente, pero esenciales para la subsistencia de un núcleo de población.

Los dos aspectos mencionados constituyen únicamente unas reflexiones que pretenden señalar algunos puntos no aclarados de la distinción entre bienes comunales y de propios. De ellas podemos obtener una serie de características comunes de cada uno de estos bienes.

- Teniendo en cuenta las precisiones realizadas anteriormente un bien comunal regulado en la legislación de régimen local es aquel bien 
cuya titularidad es del Municipio y el aprovechamiento corresponde a todos los vecinos, salvo la previsión del artículo 75.4 del Texto Refundido de la Ley de Régimen Local, y es gratuito, es decir, no produce renta en el sentido mencionado, aunque es posible fijar una cuota anual con las condiciones que impone el artículo 77 de la citada ley o se adjudiquen mediante precio, conforme el artículo 75.3 de la misma.

- La categoría de bien de propios comprende tanto los bienes cuya titularidad pertenece al Municipio y pueden constituir fuente de renta, o aquellos que con carácter residual configura el artículo 7 del Reglamento de Bienes de 13 de junio de 1986, como los bienes no comprendidos en la categoría anterior por una excesiva rigidez en su delimitación.

2. Los bienes comunales se definen como aquellos bienes cuya titularidad pertenece al Municipio (9) y el aprovechamiento a los vecinos; pero esta definición es meramente descriptiva y no expresa jurídicamente los derechos de los vecinos y del Municipio. De esta forma, se ha discutido si estos bienes son propiedad municipal, vecinal o una propiedad en la que concurren los derechos de los vecinos y del Municipio.

Considero que las tres posibilidades son inadecuadas, al menos de forma absoluta, puesto que la calificación jurídica depende de los diferentes supuestos fácticos presentes en cada momento y el grado de evolución de los mismos. Comprobemos esta afirmación con un caso concreto: los montes vecinales en mano común. Estos montes constituyen una comunidad germánica de propietarios, cuyos titulares son los comuneros y no un ente diferente, pero si le otorgamos a esa comunidad personalidad jurídica, desaparece como tal, pasando el patrimonio al nuevo ente con una afección expresa a ese fin, que determinó su constitución, y articulando los derechos y obligaciones de los antiguos comuneros a través de los derechos y obligaciones de los socios; puede ocurrir además que para atender a los gastos comunes destine el nuevo ente algunos bienes a producir renta, y que si no es suficiente, aplicando un criterio semejante al del artículo 393 del Código Civil, se fije el pago de una cantidad proporcional a los beneficios percibidos; incluso, en caso de que la voluntad de la nueva persona se independizara y no cumpliese sus fines podría ocurrir que parte de los socios prescribieran a su favor, si cumplian las reglas de Derecho privado. Como se ha podido comprobar, el supuesto descrito comprende varios tipos de bienes: bienes del ente destinados al sostenimiento de las cargas comunes y los bienes no destinados a las cargas comunes que pueden definirse como aquellos bienes titularidad

(9) Es curioso que en la nueva legislación de régimen local, a diferencia de la anterior, no exista una declaración expresa de la titularidad municipal. 
de la persona jurídica cuyo aprovechamiento obligatoriamente pertenece a los socios y es gratuito porque carece de sentido cobrar a las personas que la integran, lo que no quiere decir que para sostener las cargas comunes se prohíba realizar repartos con los criterios mencionados. Pero, continuando con la evolución de dicho ente, imaginemos que esa persona jurídica que agrupa los montes vecinales se dedica a comercializar los productos y a construir una serie de fábricas de transformación, entranado nuevos socios dedicados a mantener esa industria; si este nuevo fin adquiere importancia dentro de la persona jurídica puede ocurrir que los socios dedicados a mantener las fábricas de comercialización o transformación obtengan menos beneficios que los que explotan los montes, teniendo todos ellos los mismos derechos; entonces puede decidirse para compensar al resto de los socios que aquellos que aprevechen los montes paguen un canon, que nunca podrá ser elevado, puesto que sería contraria a la propia finalidad de la unión.

Desde este punto de vista la discusión de la configuración jurídica de los bienes comunales adquiere otro sentido porque el punto de interés reside en la relación de la personalidad jurídica con la comunidad de bienes. En nuestro Derecho existen bastantes ejemplos que revelan esta relación. Este es el caso de una comunidad de bienes y las cooperativas de explotación comunitaria de la tierra reguladas en la Ley de Cooperativas de 2 de abril de 1987; esta cooperativa tiene personalidad jurídica, perteneciendo el patrimonio a esta nueva persona, no a los socios, y articulando los derechos a través de los derechos de cada socio, sin embargo, si no tuviera personalidad jurídica estaríamos ante una comunidad de bienes (10).

Una evolución similar, aunque con diferencias, ha sufrido el patrimonio del Municipio. Inicialmente todos los bienes pertenecían a los vecinos y dentro de este patrimonio se distinguian entre los bienes dedicados al sostenimiento de las cargas comunes y los destinados al sostenimiento económico de sus propietarios; al pasar a un nuevo ente los derechos reales municipales, y quedar esas personas integradas en ella, los derechos de los propietarios se transforman en derechos y obligaciones de vecinos y el patrimonio aprovechado directamente por ellos queda afectado al sostenimiento de los vecinos y no de las cargas comunes. De esta forma no existe un derecho independiente cuyo titular es una comunidad diferente del Municipio en la que están integrados todos los vecinos, sino que el patrimonio pertenece al ente local y cada persona que sea vecino tiene ese derecho

(10) Citemos en este sentido el artículo 1.669 del Código civil:

«No tendrán personalidad juridica las sociedades cuyos pactos se mantengan secretos en los socios, y en que cada uno de estos contrate en su propio nombre con los terceros.

Esta clase de sociedades se regirá por las disposiciones relativas a la comunidad de bienes.» 
como parte del ente. Desde este punto de vista se entiende que en las leyes de régimen local se incluya dentro del capítulo de derechos y deberes de los vecinos la referencia al derecho al aprovechamiento comunal y que los bienes comunales se definan de esa forma tan curiosa (11). En este sentido también adquieren otro significado las afectaciones tácitas o expresas de los bienes comunales.

Esta solución, como dijimos al principio, no se puede generalizar puesto que si partimos de un concepto rígido de bien comunal que no comprende todos los supuestos, los restantes casos de aprovechamientos comunales deberán articularse juridicamente de otra forma. Por ejemplo, un aprovechamiento de un bien municipal por un núcleo de población de un Municipio, que no es un bien comunal y, por tanto, no existe esa obligación jurídica de destinarlos a un aprovechamiento por parte de los vecinos, puede arrendarse o cederse a otras personas. Este resultado puede evitarse acudiendo a las reglas de Derecho privado, de forma que ese núcleo prescriba a su favor el aprovechamiento (12). Esta prescripción está permitida por nuestro ordenamiento, según el artículo 14.1 del Reglamento de Bienes de 13 de junio de 1986, y es admitida por nuestra jurisprudencia en numerosos casos, aunque la mayoria referidos a prescripciones de derechos reales absolutos pertenecientes al Municipio. En este caso estamos ante un supuesto de propiedad concurrente en el que el nudo propietario es el Municipio y la comunidad de vecinos es titular de un derecho real limitado. Todavía son posibles dos variantes más aunque no nos interesen en estos momentos: La primera, que los vecinos prescriban bienes de particulares en favor del Municipio para considerarlos como bienes comunales o que los vecinos prescriban a su favor la propiedad municipal.

Estas tres variantes podrían reducirse fácilmente a dos si se ampliase el concepto de bien comunal. En este caso no habría que acudir a la figura de una comunidad titular de un derecho real administrativo o no, sino articularlo a través de los derechos y obligaciones de los individuos integrados en esa persona jurídica. Además evitaría ciertos casos en que esta construcción es excesivamente complicada como son los supuestos de las Comunidades de Villa y Tierra, Asocios, Comunidades de Pastos, Leñas, Aguas y otras análogas reguladas en el artículo 141 del Reglamento de Organización, Funcionamiento y Régimen Jurídico de las Entidades Locales de 28 de noviembre de 1986.

(11) En la actualidad el articulo 79 de la Ley Reguladora de las Bases declara la titularidad municipal y el aprovechamiento vecinal en general, y el artículo $18.1 \mathrm{c}$ ), dentro del capítulo dedicado a los derechos y deberes de los vecinos, se incluye el derecho a acceder a esos aprovechamientos como miembros de esa persona juridica.

(12) Teniendo en cuenta además que en este supuesto quien regula y organiza este derecho real limitado no es el Ayuntamiento, sino la propia comunidad, según las normas de Derecho privado. 
3. Los bienes de propios legalmente se definen como aquellos bienes de titularidad municipal que pueden constituir fuente de ingresos y los bienes comunales como aquéllos cuyo aprovechamiento pertenece a los vecinos. El Municipio puede disponer líbremente de los primeros, en cambio no puede hacer lo mismo con los comunales dado que estos bienes están afectados a ese fin. Esta última afirmación debe hacernos reflexionar sobre la configuración de los bienes comunales.

Para ello puede ser interesante la lectura del artículo 79.3 de la Ley Reguladora de las Bases de Régimen Local de 2 de abril de 1985, que a continución se transcribe, y su comparación con la afirmación anterior:

«Son bienes de dominio público los destinados a un uso o servicio público. Tienen la consideración de comunales aquellos cuyo aprovechamiento corresponda al común de los vecinos.»

La primera parte de este artículo, prescindiendo de los bienes de dominio público destinados a un servicio público, se dedica a aquellos bienes patrimonio de la entidad destinados a un uso público y la segunda parte a aquellos bienes pertenecientes al Municipio destinados a un uso del común de vecinos. En ambos casos es necesaria una afectación y una desafectación a ese fin y tienen las mismas notas, según el artículo 80.1 de la misma Ley. De este parecido nos surge la pregunta de si estos bienes no son unos bienes destinados a un uso público exclusivamente vecinal, aunque este uso público tenga una fundamentación diferente.

La Ley Reguladora de Bases de Régimen Local califica a los bienes comunales como bienes de dominio público, pero debe advertirse que la declaración inequívoca de demanialialidad se ignora en el artículo 47.2 l) de la propia Ley. Ello puede entenderse como una declaración de que son bienes demaniales, pero que tienen una fundamentación diferente a los otros dos grupos de bienes demaniales (13).

Con esta calificación como bienes demaniales se entendería que los bienes comunales, que pertenecieron inicialmente a los vecinos y cuya titularidad se traspasó posteriormente al Municipio, queden destinados a esos fines primitivos de la comunidad y que los antiguos comuneros conserven el derecho a esos aprovechamientos.

Como se ha podido deducir de la lectura de estas meras reflexiones es necesario un estudio en profundidad de la fundamentación y distinción de los distintos bienes municipales, alejándonos de toda posible definición legal o doctrinal rígida.

(13) De esta forma también se entenderia la discordancia existente entre el artículo 132 de la Constitución y la Ley de Bases. 